'Department of Digestive Diseases, Huashan Hospital, Fudan University, Shanghai, China.

${ }^{2}$ Ministry of Education Key Laboratory of Contemporary Anthropology and State Key Laboratory of Genetic Engineering, School of Life Sciences and Institutes of Biomedical Sciences, Fudan University, Shanghai, China.

${ }^{3}$ Eastern Hepatobiliary Surgery Hospital, Second Military Medical University, 225 Changhai Road, Shanghai 200438, China. ${ }^{4}$ Key Laboratory of Medical Molecular Virology of MOE/ $\mathrm{MOH}$ and Collaborative Innovation Center of Genetics and Development, Institutes of Biomedical Sciences and Department of Immunology of Shanghai Medical School, Fudan University, 138 Yixueyuan Road, Shanghai 200032, China.

\#These authors contributed equally to this work.

Fundings: This work was supported by the grant fromthe Ministry of Science and Technology of China (No. 2012CB910104)

Recibido el 21 de octubre de 2015, aceptado el 21 de enero de 2016.

Corresponding author: Jun Zhang, Ph.D. Department of Digestive Diseases, Huashan Hospital, Fudan University.

12 Middle Wulumuqi Rd. Shanghai 200040 China

Tel \& Fax: 86-21-52888236 archsteed@gmail.com

\section{Association between microRNA single nucleotide polymorphisms and the risk of hepatocellular carcinoma}

\author{
WENSHUAI LI ${ }^{1 \#}$, YANYUN MA ${ }^{2 \#}$, DEQING ZENG ${ }^{1}$, \\ JUN ZHANG ${ }^{*}$, RUI WANG ${ }^{1,2}$, JINGYI HU ${ }^{1}$, DONGQIN YANG ${ }^{1}$, \\ HEPING HU ${ }^{3}$, JIUCUN WANG ${ }^{2}$, JIE LIU ${ }^{1,4}$
}

\begin{abstract}
Background: Hepatocellular carcinoma (HCC) has a high morbidity and mortality. Single nucleotide polymorphisms (SNPs) of microRNA (miRNA) may be associated with the susceptibility to develop certain malignant tumors. Aim: To study the association between SNPs of miRNA and hepatocellular carcinoma in peripheral blood samples. Material and Methods: Three SNPs in miRNA were studied in peripheral blood samples of 498 patients with HCC and 520 controls. Results: A significant association was observed between rs13299349 in miRNA3152 and HCC. AA genotype or A allele were significantly associated with increased risk of HCC. A allele was associated with the size and number of tumor foci. There was also a relationship between rs 10061133 in miRNA449b and HCC. The G allele was significantly associated with increased risk of HCC compared with A allele. Conclusions: This study links rs13299349 in miRNA3152 and rs10061133 in miRNA449b with the risk of developing HCC.
\end{abstract}

(Rev Med Chile 2016; 144: 508-515)

Key words: Carcinoma, Hepatocellular; MicroRNAs; Polymorphism, Genetic; Polymorphism, Single Nucleotide.

\section{Asociación entre polimorfismos de un nucleótido en microRNA circulante y riesgo de carcinoma hepatocelular}

Antecedentes: El carcinoma hepatocelular (CHC) tiene una alta morbilidad $y$ mortalidad. Polimorfismos de un nucleótido (SNP) presentes en el microRNA (miRNA) circulante pueden asociarse a ciertos tumores. Objetivo: Estudiar la asociación entre la presencia de SNPs en miRNA circulante y la presencia de carcinoma hepatocelular. Material y Métodos: Se determinó la presencia de tres SNP en microRNA de sangre periférica en 498 pacientes con CHC y 520 controles. Resultados: El SNP rs13299349 en el miRNA3152 se asoció con CHC. El genotipo AA o el alelo A se asociaron con un riesgo mayor de presentar un CHC. El alelo A se asoció además con el tamaño y número de focos del tumor. Se observó también una relación entre el SNP rs10061133 en el miRNA449b y HCC. En este caso, el alelo G se relacionó con un mayor riesgo de CHC. Conclusiones: Los SNP rs13299349 en el miRNA3152 y rs10061133 en el miRNA449b se asocian al riesgo de desarrollar $\mathrm{CHC}$. 
$\mathrm{H}$ epatocellular carcinoma (HCC) is the most common type of primary liver cancer with high fatality. It is estimated that the incidence of new HCC cases is approximately over half a million per year with 500,000 deaths occurring every year worldwide ${ }^{1,2}$. This is mainly due to HCC usually being diagnosed at an advanced stage due to a difficult early diagnosis. Although extensive efforts have been done in research related to both diagnosis and treatment, mortality remains third for cancer-related death in the world. Therefore, new diagnostic and prognostic biomarkers for HCC are of paramount significance.

MicroRNAs (miRNAs) are a class of small non-coding RNA (19-24 nucleotides) regulating target genes at a post-transcriptional level, which inhibits the mRNA translation or cause the destruction of mRNA. Furthermore, accumulating evidence indicated that single nucleotide polymorphisms (SNPs) in miRNAs may affect the miRNA binding to target gene and, consequently, may result in the alteration of protein expression ${ }^{3,4}$. Therefore, SNPs within miRNA were related to the risk of various diseases, such as diabetes ${ }^{5}$ or Parkinson Disease ${ }^{6}$, in which cancers should be specifically mentioned ${ }^{7,8}$.

Some researches revealed that miR-3152 and miR-449 are involved in cancer ${ }^{17-20}$. MiR-3152 is up regulated in PDAC (pancreatic ductal adenocarcinoma), and miR-449 is down-regulated or lost in gastric cells, lung adenocarcinoma cells and testicular cancer cells. So, it is possible to connecting these SNPs in miRNAs and HCC to figure out whether relation exists or not. Therefore, this large-scale sample study ( 498 vs 520 ) aims at identifying whether rs13299349 in miR-3152 and rs2620381 in miR-449 are associated with susceptibility to HCC.

\section{Material and Methods}

\section{Study subjects}

In this study, HCC patients diagnosed either by histopathologic or imaging evidence, were enrolled from Shanghai Huashan Hospital and Eastern Hepatobiliary Surgery Hospital. Healthy individuals without any history of neoplasms or other severe diseases were ramdomly recruited as controls from the Taizhou Longitudinal Study.
Basic characteristics of all enrolled subjects, including age, gender,family history, medication, smoking status, and alcohol intake were collected with questionnaires conducted by well-trained interviewers. For HCC patients, clinicopathologic characteristics and indexes were also collected, such as the number, size, pathologic type/grade and metastasis of the tumor, as well as the serum levels of alpha-fetoprotein (AFP), hepatitis B surface antigen (HBsAg), HBV-DNA, alanine aminotransferase (ALT), aspartate transaminase (AST) and total bilirubin (TB). Informed consent for sample collection and subsequent analysis was obtained from each subject at recruitment. The whole procedure of our study was approved by local ethics review board and fulfilled the international ethical standards.

\section{DNA extraction and genotyping assay of SNPs within miRNA}

Genomic DNA was extracted from peripheral blood with AxyPrep ${ }^{\mathrm{TM}}$ Blood Genomic DNA Miniprep Kit (Axygen Biosciences). The technology of nucleic acid electrophoresis and concentration determination were used to ensure the quality and quantity of DNA samples. Genotyping of SNPs in miRNAs was performed by SequenomMassARRAY technology. The amplification and extension primers of SNPs, listed in Table 1, were designed by MassARRAY Assay Design Software and synthetized by Invitrogen Corporation Shanghai Representative Office. Sequencing was performed on MassARRAY Compact System (SEQUENOM Corporation) and the data were analyzed by TYPER Analyzer software 4.0.

\section{Statistical analysis}

All statistical analyses were performed using Statistical Package for Social Sciences (SPSS, version 19.0) and Microsoft Excel. Genotype frequencies study and and control groups were assessed for Hardy-Weinberg equilibrium by Pearson chi-square test of goodness-of-fit. Binary logistic regression analysis was conducted to investigate the association between the genotypes/allele types of the miRNA SNPs and the susceptibility to HCC after adjusting for confounders. In subsequent assessment of the relationship between the genotypic/allelic frequencies of miRNA SNPs and qualitative clinicopathologic characteristics in HCC 
Table 1. The miRNA SNPs investigated in this study

\begin{tabular}{|c|c|c|c|c|c|c|c|c|}
\hline SNP ID & $\begin{array}{l}\text { Substi- } \\
\text { tutes }\end{array}$ & $\begin{array}{c}\text { SNP } \\
\text { location }\end{array}$ & $\begin{array}{l}\text { Chromosome } \\
\text { start-stop } \\
\text { site }\end{array}$ & miRNA & Location & $\begin{array}{l}\text { Amplification } \\
\text { primer } 2\end{array}$ & $\begin{array}{c}\text { Amplification } \\
\text { primer } 1\end{array}$ & $\begin{array}{c}\text { Extension } \\
\text { primer }\end{array}$ \\
\hline \multirow[t]{3}{*}{ rs13299349 } & $A / G$ & 18573360 & chr9: & hsa-mir- & mat & ACGTTGGATG & ACGTTGGATG & tcctTGCAGAG \\
\hline & & & $18573304-$ & 3152 & & AGACTAGGCT & АСТTССТССТ & TTATTGCCC \\
\hline & & & 18573377 & & & TCCCTGTGTT & TAGATGGGTG & \\
\hline \multirow[t]{3}{*}{ rs10061133 } & $A / G$ & 54466544 & chr5: & hsa-mir- & mat & ACGTTGGATG & ACGTTGGATG & GAATCAGGTAGG \\
\hline & & & 54466474- & $449 b$ & & TAGTTGTGGC & AATCGGCAGT & CAGTGTAT \\
\hline & & & 54466570 & & & TGCTGACTTG & GACCTGAATC & \\
\hline
\end{tabular}

patients, Pearson chi-square test of independence was performed. For quantitative clinical indexes, ANOVA tests were carried out when the data had homogeneity of variance, while nonparametric test was applied to analyze the data with heterogeneity of variance or non-normal distribution. A p-value $<0.05$ was considered as significant, and all statistical tests were two-sided.

\section{Results}

\section{Sample overview}

There were 1,018 subjects enrolled in our study, including 498 HCC patients and 520 controls. In the cases group, $\mathrm{HBs} A g$ positive patients accounted for $82.7 \%$. General characteristics of all subjects are listed in Table 2. It was shown that age, gender and smoking status were significantly different between cases and controls, while drinking status showed no difference between both groups.

In this study, we investigated 2 microRNA SNPs, that is rs13299349 and rs10061133. The two SNPs were successfully genotyped in 1,015 and 1,010 subjects respectively.

\section{Association between the miRNA SNPs and susceptibility to hepatocellular carcinoma}

After adjusting for confounding factors such as sex, age and smoking by binary logistic regression, we found that there was a significant association between rs13299349 in miRNA3152 and the risk of HCC (Table 3). The genotype of AA or A allele associated significantly to an increased risk of HCC (AA: OR $(95 \%$ CI $)=5.286(1.059-26.379)$, $\mathrm{P}=0.042$; A allele: $\mathrm{OR}(95 \% \mathrm{CI})=1.386(1.031-$
1.864), $\mathrm{P}=0.031$ ) compared with the genotype of AG+GG or G allele. This trend was also showed in the HBV-related HCC patients (AA: OR $(95 \%$ CI $)=9.657(1.105-84.395) ;$ A allele: OR $(95 \%$ CI $=1.396$ (1.008-1.934), $\mathrm{P}=0.045)$. Thus, this indicated that the recessive model might suit its role in the formation of the HCC and the HBV-related HCC.

Moreover, we found that there was statistically significant association between rs10061133 in miRNA449b and the susceptibility to HCC (Table 3 ). The $\mathrm{G}$ allele was significantly associated with increased risk of HCC (G allele: OR $(95 \% \mathrm{CI})=$ 1.234 (1.002-1.520), $\mathrm{P}=0.048)$ compared with $\mathrm{A}$ allele. There was no significance in AG and GG genotype patients.

\section{Association between the miRNA SNPs and clinical indexes in HCC patients}

As shown in Table 4, the relation between the SNPs and the clinical indexed consisted of the number, size, AFP, total bilirubin, direct bilirubin, indirect bilirubin, ALT, AST, HBV-DNA, CEA and CA199 was also explored. However, it was only detected that rs 13299349 was significantly related to the size and the number of tumor foci. The proportion of tumor size $\geq 5 \mathrm{~cm}$ in A allele was $71.2 \%$, whereas in $\mathrm{G}$ allele it was $56.3 \%(\mathrm{P}=0.036)$. In the meantime, the proportion of the multiple number of tumor foci in AA, GG and AG genotype was $50 \%, 13.99 \%$ and $3.51 \%$ respectively $(\mathrm{P}=0.003)$. Both results were consistent with the correlation of AA genotype/A allele to the increased risk of HCC. The other SNPs had no association to the clinical indexes. 
The association between miRNA SNPs and HCC - W. Li et al

Table 2. General characteristics of hepatocellular carcinoma patients and unaffected controls

\begin{tabular}{|c|c|c|c|}
\hline & $\begin{array}{c}\text { Cases } \\
(n=498) \\
\text { No. }(\%) \text { or mean } \pm \text { SD }\end{array}$ & $\begin{array}{c}\text { Controls } \\
(n=520) \\
\text { No. }(\%) \text { or mean } \pm \text { SD }\end{array}$ & P value \\
\hline Age (years) & $60.11 \pm 11.487$ & $54.33 \pm 11.233$ & $<0.001 *$ \\
\hline \multicolumn{4}{|l|}{ Gender } \\
\hline Male & $81 \quad(16.3)$ & 154 (29.6) & \multirow[t]{2}{*}{$<0.001 *$} \\
\hline Female & 417 (83.7) & 366 (70.4) & \\
\hline Smoking status & 493 & & \multirow{3}{*}{$0.004^{*}$} \\
\hline Never & 315 (63.9) & $286 \quad(55.0)$ & \\
\hline Ever & 178 (36.1) & $234(45.0)$ & \\
\hline Drinking status & 490 & & \multirow{3}{*}{0.098} \\
\hline Never & 352 (70.7) & 398 (76.5) & \\
\hline Ever & 138 (27.7) & 122 (23.5) & \\
\hline $\mathrm{HBsAg}$ & 479 & & \\
\hline Negative & $83 \quad(17.3)$ & & \\
\hline Positive & $396 \quad(82.7)$ & & \\
\hline $\mathrm{HCV}$ & 454 & & \\
\hline Negative & $17 \quad(3.7)$ & & \\
\hline Positive & $437 \quad(96.3)$ & & \\
\hline Size of tumor foci & 278 & & \\
\hline$<5 \mathrm{~cm}$ & $117 \quad(42.1)$ & & \\
\hline$\geq 5 \mathrm{~cm}$ & $161 \quad(57.9)$ & & \\
\hline Number of tumor foci & 278 & & \\
\hline Single & $248 \quad(89.2)$ & & \\
\hline Multiple & $30(10.8)$ & & \\
\hline \multicolumn{4}{|l|}{ Serum levels of tumor markers } \\
\hline ALT (U/L, in 495 subjects) & $59.42 \pm 87.97$ & & \\
\hline AST (U/L, in 492 subjects) & $63.62 \pm 88.68$ & & \\
\hline \multicolumn{4}{|l|}{$\operatorname{AFP}(\mu \mathrm{g} / \mathrm{L}, \mathrm{n}=488)$} \\
\hline$<20 \mu \mathrm{g} / \mathrm{L}$ & $182 \quad(37.3)$ & & \\
\hline$\geq 20 \mu \mathrm{g} / \mathrm{L}$ & $306 \quad(62.7)$ & & \\
\hline CEA $(\mu \mathrm{g} / \mathrm{L}, \mathrm{n}=464)$ & $5.38 \pm 31.81$ & & \\
\hline CA $199(\mathrm{U} / \mathrm{ml}, \mathrm{n}=455)$ & $43.03 \pm 76.41$ & & \\
\hline \multicolumn{4}{|l|}{ HBV-DNA $(n=401)$} \\
\hline$\geq 1.000 \mathrm{IU} / \mathrm{mL}$ & $170 \quad(43.4)$ & & \\
\hline$<1.000 \mathrm{IU} / \mathrm{mL}$ & $231 \quad(57.6)$ & & \\
\hline (IU/mL, in subjects) & $1588234.48 \pm 4361987.758$ & & \\
\hline
\end{tabular}

${ }^{*} \mathrm{p}$ value less than 0.05 . 
Table 3. Association between genotypes/alleles of miR-3152 rs13299349 and miR-449b rs 10061133 and the risk of HCC

\begin{tabular}{|c|c|c|c|c|c|c|c|}
\hline \multirow[t]{2}{*}{ Genotype } & \multirow{2}{*}{$\begin{array}{l}\text { Control } \\
\text { Number } \\
(\%)\end{array}$} & \multicolumn{3}{|c|}{ HCC patients } & \multicolumn{3}{|c|}{ HCC patients with HBV } \\
\hline & & $\begin{array}{l}\text { Number } \\
\text { (\%) }\end{array}$ & OR $(95 \% \mathrm{CI})^{\mathrm{a}}$ & $\mathbf{P a}$ & $\begin{array}{c}\text { Number } \\
(\%)\end{array}$ & OR $(95 \% \mathrm{CI})^{\mathrm{a}}$ & $\mathbf{P a}$ \\
\hline rs13299349 & $n=520$ & $n=495$ & & & $n=394$ & & \\
\hline GG & $398(76.5)$ & $402(81.2)$ & 1 & & $320(81.2)$ & 1 & 0 \\
\hline AA & $9(1.7)$ & $2(0.4)$ & $1.260(0.908-1.750)$ & 0.167 & $1(0.3)$ & $1.230(0.860-1.761)$ & 0.257 \\
\hline GA & $113(21.7)$ & $91(18.4)$ & $0.227(0.045-1.159)$ & 0.075 & $73(18.5)$ & $0.122(0.014-1.088)$ & 0.060 \\
\hline $\begin{array}{l}\text { Dominant model } \\
\text { (AA+AG vs } G G)\end{array}$ & & & $1.344(0.974-1.855)$ & 0.072 & & $1.331(0.936-1.894)$ & 0.112 \\
\hline $\begin{array}{l}\text { Recessive model } \\
\text { (AA vs } A G+G G \text { ) }\end{array}$ & & & $5.286(1.059-26.379)$ & $0.042 *$ & & $9.657(1.105-84.395)$ & $0.040^{*}$ \\
\hline G & $729(70.6)$ & $739(74.8)$ & 1 & & $581(73.7)$ & 1 & \\
\hline A & $303(29.4)$ & $249(25.2)$ & $1.386(1.031-1.864)$ & 0.031 * & $207(26.3)$ & $1.396(1.008-1.934)$ & $0.045^{*}$ \\
\hline rs1006113 & $n=516$ & $n=494$ & & & $n=394$ & & \\
\hline AA & $257(49.8)$ & $278(56.3)$ & 1 & & $215(54.6)$ & 1 & \\
\hline GG & $44 \quad(8.5)$ & $33(6.7)$ & $1.231(0.934-1.621)$ & 0.140 & $28(7.1)$ & $1.119(0.830-1.510)$ & 0.460 \\
\hline AG & $215(41.7)$ & $183(37.0)$ & $0.806(0.478-1.360)$ & 0.419 & $151(38.3)$ & $0.773(0.440-1.357)$ & 0.370 \\
\hline $\begin{array}{l}\text { Dominant model } \\
\text { (AA vs } A G+G G \text { ) }\end{array}$ & & & $1.274(0.980-1.657)$ & 0.071 & & $1.167(0.878-1.553)$ & 0.288 \\
\hline $\begin{array}{l}\text { Recessive model } \\
\text { (AA+AG vs GG) }\end{array}$ & & & $1.398(0.849-2.301)$ & 0.188 & & $1.379(0.806-2.360)$ & 0.241 \\
\hline A & 729 (70.6) & 739 (74.8) & 1 & & $581(73.7)$ & 1 & \\
\hline G & $303(29.4)$ & $249(25.2)$ & $1.234(1.002-1.520)$ & $0.048^{*}$ & $207(26.3)$ & $1.166(0.931-1.460)$ & 0.182 \\
\hline
\end{tabular}

${ }^{a}$ ORs and $p$ values were all obtained after adjusting for age, gender and smoking status. ${ }^{*} p$ value less than 0.05 .

Table 4. Association between the genotypic/allelic frequencies of miRNA SNPs and clinical indexes in HCC patients

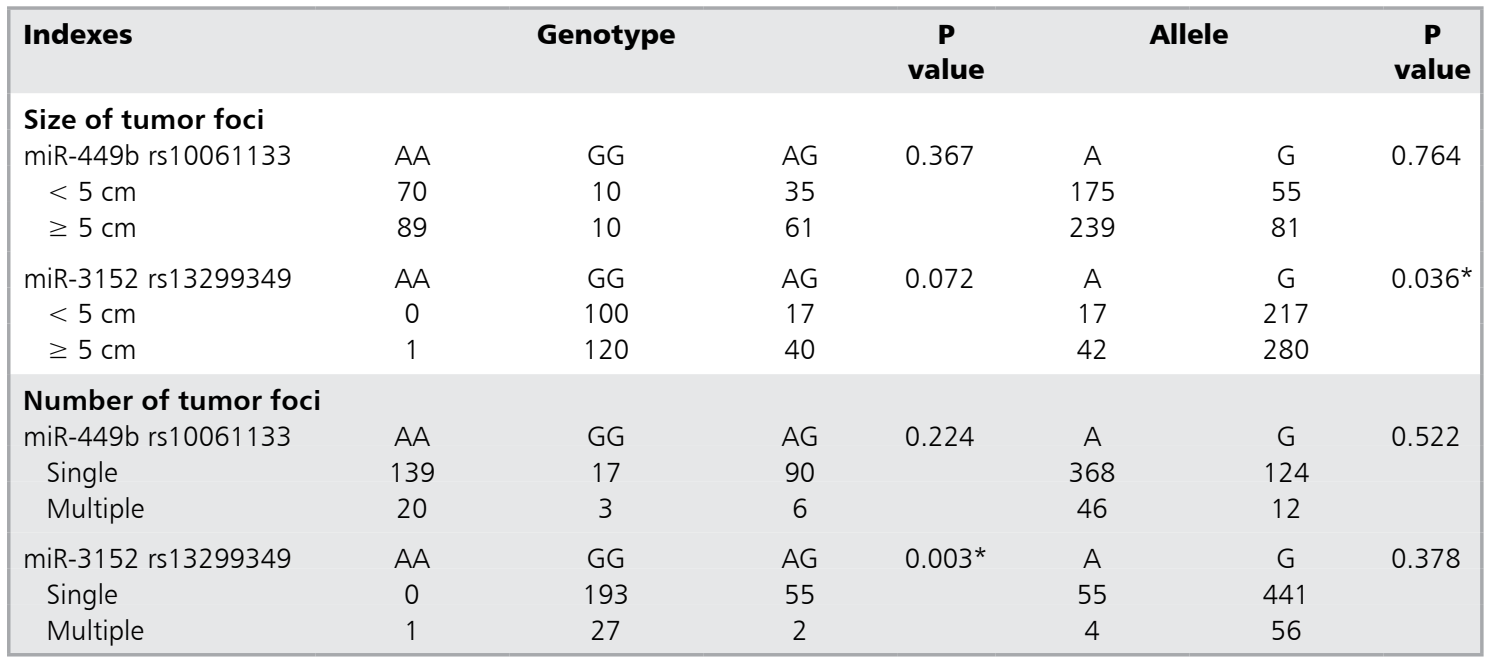




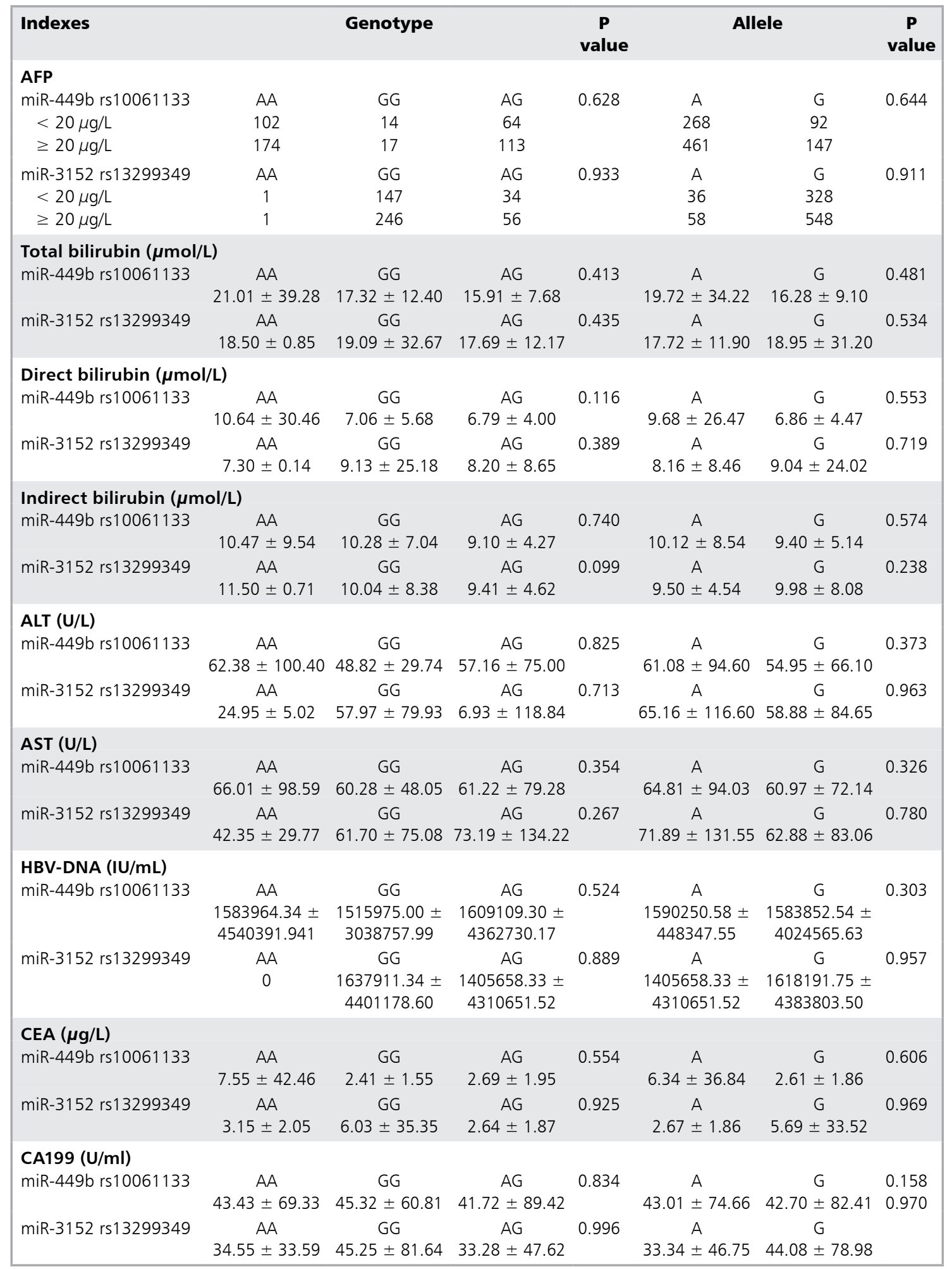

*P value less than 0.05 


\section{Discussion}

Morbidity and mortality of liver tumors are extremely high and increasing rapidly. Therefore, early diagnosis and intervention in cancer are very crucial and urgent. Epidemiological investigations show that the prevalence of HCC varies in different geographical regions, with relatively higher incidence in many Asian countries and Sub-Saharan Africa, especially in China, where almost half of the worldwide cases and deaths occur. Major risk factors associated with HCC include chronic HBV or HCV infection, excessive alcohol intake, alcoholic and nonalcoholic steatohepatitis, exposure to Aspergillus flavus toxin $\mathrm{B}$, disorders of the immune system, etc ${ }^{9}$. Eighty percent of HCC patients in China have HBV infection, while only a small part of the population infected with HBV will progress into HCC. Meanwhile, research also shows that individual genetic factors contribute improtantly to hepatocarcinogenesis ${ }^{10}$. For instance, it has been certified that polymorphisms of cytochrome P450 2E1 (CYP2E1) plays a crucial role in cigarette smoking-related hepatocarcinogenesis, which is of great importance in the metabolism of many carcinogens.

MicroRNAs (miRNAs), a group of small noncoding RNAs of about 22 nucleotides, play a significant role in the regulation of gene expression. Mature miRNAs, originating from long pri-miRNAs and pre-miRNAs, complementarily bind to the 3' untranslated regions (UTRs) of target mRNAs, and control many biological pathways such as cell growth, differentiation, metabolism and apoptosis ${ }^{11,12}$. Alteration of miRNA expression is observed in the formation and development of human diseases, disturbing the expression, maturation and target recognition of miRNAs, consequently alters protein expression and leads to phenotypic differences, contributing to the different risks of human diseases, including malignant tumors like HCC ${ }^{13-15}$. Therefore, SNPs in miRNAs are critical genetic factors in the initiation and progression of tumors.

miRNA3152 has been studied in a previous research enrolling 53 PDAC patients vs 30 pancreatitis and 13 healthy control, validating that miRNA3152 is upregulated in PDAC ${ }^{16}$. But it has not mentioned any SNP. To the best of our knowledge, in our 498 vs 520 case-control study, we have firstly revealed that the genotype of AA or A allele of rs13299349 in miRNA3152 significantly associated with the susceptibility of HCC, indicating rs13299349is a risky factor to HCC. Another important result is that rs13299349 is correlated to the size and number of tumor foci. It is shown that the structure of miRNA3152 with A allele of rs13299349 has a larger reduction of free energy $(\Delta \mathrm{G}=-45.6 \mathrm{kcal} / \mathrm{mol})$ compared with $\mathrm{G}$ allele $(\Delta \mathrm{G}=-41.7 \mathrm{kcal} / \mathrm{mol})$ by Mfold web server, indicating the $\mathrm{A}$ allele may increase the stability of miRNA3152 that results in an overexpression of miRNA3152. Therefore, at the same time, our study got a consistent result with the PDAC, suggesting that rs13299349 in miRNA3152 might be an advantageous element to the cancers.

In addition, our study indicates that miRNA449 might act as a tumor suppressor. It has been verified that miR-449 is down-regulated or lost in gastric cells, lung adenocarcinoma cell and testicular cancer cells ${ }^{17-20}$. In addition, our research demonstrates for the first time that in miRNA449b (rs10061133), G allele is significantly associated with an increased risk of susceptibility to HCC compared with A allele. However, the genotype of GG or AG shows no statistical significance, which may be not related to susceptibility of HCC.

To sum up, this study explores that rs13299349 in miRNA3152 and $\mathrm{G}$ allele rs10061133 in miRNA449b are significantly related to the susceptibility of HCC, which might be used in companion with other significant miRNA SNPs as a prediction tool. To further understand the results of our study and apply the basic research to clinic, more functional studies of rs13299349 and rs10061133 are required.

In conclusion, this study shows an association between the miRNA SNPs and the susceptibility to hepatocellular carcinoma, hoping to reveal some roles and mechanisms of SNPs within miRNAs in the occurrence and development of primary liver cancer. We expect that our efforts and findings will facilitate the use of miRNA SNPs in early detection and confirmation of HCC, as well as an effective treatment.

Acknowledgements: This work was supported by the grant from the Ministry of Science and Technology of China (No. 2012CB910104). The funder had no role in the study design, data collection and analysis, decision to publish or preparation of the manuscript. 


\section{References}

1. Parkin DM. Global cancer statistics in the year 2000 . Lancet Oncol 2001; 2 (9): 533-43.

2. El-Serag HB. Hepatocellular carcinoma. N Engl J Med 2011; 365 (12): 1118-27.

3. Bartel DP. MicroRNAs: genomics, biogenesis, mechanism, and function. Cell 2004; 116 (2): 281-97.

4. Ambros $\mathrm{V}$. The functions of animal microRNAs. Nature 2004; 431 (7006): 350-5.

5. Lv K, Guo Y, Zhang Y, Wang K, Jia Y, Sun S. Allele-specific targeting of hsa-miR-657 to human IGF2R creates a potential mechanism underlying the association of ACAA-insertion/deletion polymorphism with type 2 diabetes. Biochem Biophys Res Commun 2008; 374 (1): 101-5.

6. Wang G, van der Walt JM, Mayhew G, Li YJ, Zuchner $\mathrm{S}$, Scott WK, et al. Variation in the miRNA-433 binding site of FGF20 confers risk for Parkinson disease by overexpression of alpha-synuclein. Am J Hum Genet 2008; 82 (2): 283-9.

7. Drakaki A, Iliopoulos D. MicroRNA Gene Networks in Oncogenesis. Curr Genomics 2009; 10 (1): 35-41.

8. Zhang L, Huang J, Yang N, Greshock J, Megraw MS, et al. microRNAs exhibit high frequency genomic alterations in human cancer. Proc Natl Acad Sci U S A 2006; 103 (24): 9136-41.

9. Bosch FX, Ribes J, Borras J. Epidemiology of primary liver cancer. Semin Liver Dis 1999; 19 (3): 271-85.

10. Sanyal AJ, Yoon SK, Lencioni R. The etiology of hepatocellular carcinoma and consequences for treatment. Oncologist 2010; 15 Suppl 4: 14-22.

11. Ambros V. MicroRNA pathways in flies and worms: growth, death, fat, stress, and timing. Cell 2003; 113 (6): 673-6.
12. Zamore PD, Haley B. Ribo-gnome: the big world of small RNAs. Science 2005; 309 (5740): 1519-24.

13. Hu Z, Liang J, Wang Z, Tian T, Zhou X, et al. Common genetic variants in pre-microRNAs were associated with increased risk of breast cancer in Chinese women. Hum Mutat 2009; 30 (1): 79-84.

14. Peng S, Kuang Z, Sheng C, Zhang Y, Xu H, Cheng Q. Association of microRNA-196a-2 gene polymorphism with gastric cancer risk in a Chinese population. Dig Dis Sci 2010; 55 (8): 2288-93.

15. Wang R, Zhang J, Jiang W, Ma Y, Li W, Jin B, et al. Association between a Variant in MicroRNA-646 and the Susceptibility to Hepatocellular Carcinoma in a Large-Scale Population. ScientificWorld Journal 2014; 2014: 312704.

16. Mardin WA, Dhayat S, Willscher E. Serum microARN signatures differentiate pancreatic ductal adenocarcinoma from pancreatitis and healthy pancreas. J Am Coll Surgeons 2011; 213; S134-S136.

17. Lize M, Pilarski S, Dobbelstein M. E2F1-inducible microRNA 449a/b suppresses cell proliferation and promotes apoptosis. Cell Death Differ 2010; 17 (3): 452-8.

18. Bou KT, Futoma-Kazmierczak E, Jacobsen A, Krogh A, Bardram L, Hother C, et al. miR-449 inhibits cell proliferation and is down-regulated in gastric cancer. Mol Cancer 2011; 10: 29.

19. Marcet B, Chevalier B, Luxardi G, Coraux C, Zaragosi LE, Cibois M, et al. Control of vertebrate multiciliogenesis by miR-449 through direct repression of the Delta/ Notch pathway. Nat Cell Biol 2011; 13 (6): 693-9.

20. Capuano M, Iaffaldano L, Tinto N, Montanaro D, Capobianco V, Izzo V, et al. MicroRNA-449a overexpression, reduced NOTCH1 signals and scarce goblet cells characterize the small intestine of celiac patients. PLoS One 2011; 6 (12): e29094. 